\title{
Reflections on the first twenty-five years of the University of Malawi College of Medicine
}

\author{
Adamson S. Muula ${ }^{1,2}$, Wakisa Mulwafu ${ }^{3}$, Diston Chiweza ${ }^{4}$, Ronald Mataya ${ }^{5,6}$
}

\author{
1. Department of Public Health, School of Public Health and Family Medicine, College of Medicine, University of Malawi, Blantyre, Malawi \\ 2. African Centre of Excellence in Public Health and Herbal Medicine (ACEPHEM), University of Malawi, Blantyre, Malawi \\ 3. Department of Surgery, College of Medicine, University of Malawi, Blantyre, Malawi \\ 4. College Library, College of Medicine, University of Malawi, Blantyre, Malawi \\ 5. Department of Obstetrics and Gynaecology, College of Medicine, University of Malawi, Blantyre, Malawi \\ 6. Loma Linda University School of Public Health, Loma Linda, California, USA
}

Correspondence: Adamson S. Muula (amuula@medcol.mw)

\begin{abstract}
September 2016 marks 25 years since the College of Medicine of the University of Malawi was established. In this article we reflect on its conception, birth, adolescence, and youth. The contributions of multiple stakeholders are celebrated while being mindful of the ongoing efforts to consolidate past and current gains. For instance, the College of Medicine was, until recently, the only medical school in the country, but a new private medical school has just been opened in Lilongwe. International partnerships and wide-ranging resource mobilisation from both internal and international funders has been the hallmark of the growth and expansion of the Malawi College of Medicine. Further, the expanding needs for specialists in several clinical and non-clinical areas among the health professions calls for responsive strategies to address this and other human resources needs.
\end{abstract}

\section{The early beginnings}

In 1982, a delegation of the World Health Organization (WHO) met Malawi's Minister of Health, Mr Twaibu Sangala, to discuss the feasibility of the country establishing its own medical school. ${ }^{1}$ The team leader of the consultants was Prof. A.I. Grillo; other members were Drs H.M. Grilles and D.N. Lanthum. At a meeting that the minister hosted for the visitors, he said that the medical school would be estbalished "as soon as possible". The thinking then was that the medical school, once established, would also serve the medical doctor training needs of not only Malawi but also those of Zambia and Zimbabwe. It was not until nine years later, in 1991, that the school was established. ${ }^{2}$

It is important to mention the late Prof. John Chiphangwi's role in the establishment of the Malawi College of Medicine (COM). He was appointed project manager by the Ministry of Health, a role he fulfilled with consummate skills and tenacity. He negotiated with external universities to accept the first intake of students for their basic sciences and mobilised donors to fund not only scholarships but also infrastructure and facilities necessary for establishing a medical school. His was a monumental task indeed! Prof. Chiphangwi could have been the College's first principal and executive dean. However, noting that he had been a clinician most of his adult life and not an academic, he did not accept to take up this role until after having the opportunity to learn from the first holder of this post, the Australian Geoffrey Dahlenburg.

The College of Medicine opened its doors in September 1991 to receive the first group of undergraduate students who had, in 1986, gone to the United Kingdom for their pre-clinical studies. Over the subsequent years, further groups of students returned from the United Kingdom (the University of St Andrews in Scotland and University College London), Australia (the University of Adelaide and the Flinders University of South Australia), and South Africa (the University of Cape Town), where they had gone for part of their medical studies. The chronology of events and the rationale for this hybrid training have been previously described. $^{3-5}$

\section{Recording our history}

In 1993, Geoffrey Dahlenburg, the first Principal and Executive Dean of the COM, first reported to the world the opening of this medical school in an article published in Tropical Doctor. ${ }^{2}$ In 1994, Adelola Adeloye, the joint discoverer of the Adeloye-Odeku sub-galeal cyst ${ }^{6-9}$ and the first Head of Surgery at the COM, presented on the "hybrid"10 arrangement of training of the pacesetter students admitted to the Malawi medical school.

Dahlenburg ${ }^{2}$ reported that the students who had gone to the United Kingdom were supposed to have returned in 1989 after completing their three years of pre-clinical studies, but as preparations for their return had been delayed, they stayed two years more, with the first group only returning in 1991. Academic staff who had been recruited only started to arrive in April of that year. In short, the country was not prepared, at the time, to open a medical school with all the academic departments in situ. There were not enough academic and scientific staff to call from, and the infrastructure was limited. Both (academic staff and infrastructure) needed to be developed step by step and deliberately. The preferred strategy then was to recruit capable Malawians to start their medical education elsewhere while the groundwork was being established for the clinical years and (later on) the preclinical years.

\section{Career paths}

Robin Lumb Broadhead (otherwise fondly referred to as Chimutu ["big head"] by his students), the first Head of Paediatrics and Child Health, and Adamson Muula joined forces to describe the postgraduate paths that the initial cohorts of COM medical graduates took. ${ }^{4}$ Many of the graduates were following careers in public health or public health-related disciplines, while some joined clinical disciplines. In the years between 1992 and 2000, the path to studying public health was much clearer than clinical specialisation, the latter often meant reading for the Part 1 Membership examination of the either the Royal College of Physicians or Surgeons (MRCP/S) in the United Kingdom, or in some cases, Fellowships of Colleges of Medicine in South Africa. The basic sciences were largely orphaned, although it is important also to specifically mention John Eugenes Chisi, who read experimental anatomy for his $\mathrm{PhD}$. MMJ VOL 28 (3): September 2016 
Over the years, and far apart, other medical graduates, such as Kondwani Katundu and Chilungamo Chingwanda, have taken postgraduate paths in the basic and applied sciences of medicine, but interest in these disciplines among our graduates has been far too little to date. Going forward, we will need to reflect on this experience, talk to people (including our students), and interest more graduates to be basic scientists.

\section{Training in postgraduate histopathology}

The father of histopathology or anatomical pathology in Malawi is Ndalama George Liomba. Prof. Liomba was educated in Australia for his undergraduate studies before being admitted as Fellow of the Royal College of Pathologists (UK). Working for the Ministry of Health, he was the first head of the National AIDS Secretariat, the body that was tasked with spearheading the HIV and AIDS national response during the early years of the HIV epidemic. He was later to head the Malawi Blood Transfusion Services. While Liomba provided the in-country mentoring and training, other pathologists have trained in either Uganda or South Africa. For lack of a critical mass of pathologists and infrastructure, the country is unable to train its own pathologists.

\section{More than just medicine}

The Malawi College of Medicine is now an education and training institution of not just medical students, but also other health professions. From one Faculty of Medicine, we now have two more: the Faculty of Biomedical Sciences and Allied Health Professions and the School of Public Health and Family Medicine (the home of the largest postgraduate training programme in the University of Malawi-the Master of Public Health, MPH). We now have programmes at the degree level in physiotherapy, medical laboratory sciences, pharmacy, health services management, and upgrading degree programmes for clinical officers. Such an expansion provides opportunities for interprofessional training and clinical practice, mimicking the real-life situation within the healthcare environment, where doctors and other health professionals work together in the same space.

In a previous article, Muula has argued that Malawi needed another medical school. ${ }^{11}$ This wish was granted in 2015 when Daeyang Luke University, a private Christian educational institution, opened its medical school. Following the path that the COM took at its inception, ten students from the Daeyang Medical School were enrolled at the COM for their pre-clinical studies. These students will go back to conclude their studies at their medical school, thus completing the opening of a sister and (hopefully) competing medical school in Malawi.

\section{National postgraduate training programmes}

The COM has been deliberate in calculating the way it has established postgraduate programmes. When a critical mass of faculty had been assembled, the MPH programme was launched. Creation of the MPH programme was led by DrJohn Cameron Bowie, who joined forces with Chiwoza Bandawe, Joseph Mfutso-Bengo, Kenneth Maleta, Victor Mwapasa, Humphreys Misiri, Don Mathanga, and Steve Meshnick (of the University of North Carolina at Chapel Hill). Clinical specialisation programmes were later launched. Batumba Henry Nkume led the ophthalmologists, Robin Broadhead and Liz Molyneux spearheaded the paediatricians, Ronald Mataya and Frank Taulo the obstetricians \& gynaecologists, http://dx.doi.org/10.4314/mmj.v28i3.2
Eric Borgstein and Nyengo Mkandawire the general and orthopaedic surgeons, and Ed Zijlstra and Theresa Allain led the internists. Gregor Pollach trained anaesthetists and then handed over the mantle to Felix Namboya, while Wakisa Mulwafu led the ENT (Ear-Nose-Throat) camp. We also have a programme in Family Medicine, established by Luckson Dullie and Martha Makwero. The overall leadership in the postgraduate school has been offered by Postgraduate and Research Deans: Boniface Msamati, Eric Borgstein, Ken Maleta, Kamija Phiri, Adamson Muula, and Victor Mwapasa.

\section{Regional and international collaborations}

It is interesting that the news report of the 1982 meeting between the then Minister of Health, Dr Sangala, and the Grillo team (Grillo, Gilles, and Lanthum) stated that Malawi will "rid herself of the need to import doctors from overseas." In 1982, when there was no medical school within the country, this statement of hope and isolationism was fitting. Once we had a medical school of our own, it became apprarent that to maintain regional and international relevance and to ensure high levles of quality, our medical school needed to be outward looking. We have, therefore, imported students from the Southern African Development Community (SADC), the Economic Community of West African States (ECOWAS), the European Union, and Asia. We have similarly imported teaching and research faculty from across the world. Just like any other country, we cannot satisfy all the medical doctor needs in all areas. We import doctors and, in some cases, we export patients. That need, however, is not because we have zero production of our own medical doctors.

Why, after 25 years, do we still send patients abroad (especially to South Africa and India)? We can come up with several answers. First, patients who have the means and desire can obtain healthcare from wherever they want to obtain the services. This is not to unique to Malawi or low-income countries. But our situation is much more nuanced, as we believe many of the patients who obtain care do so through public expense. The main reason is that these people are sent to obtain medical services not yet available in the country. The improvements in diagnostic possibilities mean that we are now (more so than ever before) able to detect more congenital heart defects, more cancers, more adult heart conditions, more kidney problems requiring transplants, and more specific diagnoses after trauma.

To complete the story, we need to recognise the improvements in tissue pathological services, championed by Tamiwe Tomoka, Charles Dzamalala, and Steve Kamiza (all graduates of the COM), and expanding cancer chemotherapy services led by Leo Masamba, George Chagaluka, Richard Nyasosela (all graduates of the COM). Surgical services have always been available although the possibilities are now wider and readily accessible within the country. The absence of radiotherapy within the current infrastructure has militated against further improvement of cancer services.

Our medical school's collaboration footprint is well spread out across the world. We have been members of the following large consortia:

- The Medical Education Partnership Initititive (MEPI)

- The Southern African Consortium for Research Excellence (SACORE), a network of medical schools funded by the Wellcome Trust (UK)

- The Consortium for Advanced Research Training in Africa 
(CARTA), another grouping funded by the Wellcome Trust, in collaboration with other funders

- The African Journal Partnership Project (now African Journal Partnership Program, AJPP), through the Malawi Medical Journal $(M M J)$, a leading publication in the southern African region, which is jointly owned by the COM and the Medical Association of Malawi

- The Malaria Capacity Development Consortium (MCDC) - The Norwegian Programme for Capacity Development in Higher Education and Research for Development (NORHED), which has provided funding for antimicrobial stewardship training and research, as well as further funding for surgical capacity building

The COM hosts several research and training centres and affilitates. These include: the Blantyre Malaria Project (BMP), the Malaria Alert Centre (MAC), the MalawiLiverpool-Wellcome Trust Clinical Research Programme (MLW), the Tropical Research Unit of Excellence (TRUE), the Johns Hopkins Project in Blantyre, and the Malawi Epidemiologic and Intervention Research Unit (MEIRU). Lately, the College has been earmarked for the establishment of the African Centre of Excellence in Public Health and Herbal Medicine (ACEPHEM), through credit funding that the Malawi government has obtained from the World Bank. Our regional presence and expertise, and international relationships bear testimony to the good work that the College is doing in teaching and training doctors, as well as research.

\section{The Research Support Centre}

The COM was established on a strong research foundation. Research teams that were already working in the country were soon invited to be affiliated with the institution. New teams that emerged were encouraged to be part of the College. Teaching and community engagements were, together with research, the triad or triumvirate that the College of Medicine valued. In order to ensure that research (basic sciences, clinical, and community) was supported, the COM established the Research Support Centre (RSC) in 2006. The Centre was tasked with the organisation, coordination, and management of research and research-related resources. From 2006, the COM RSC has had the following roles:

- Research capacity building and training

- Supporting the conduct of clinical trials

- Data management

- Facilitating research dissemination for faculty members and students

\section{- Grants administration}

\section{The College Library}

Even with continuing growth and ever-increasing access of relevant medical information on the Internet and mobile electronic devices, a library continues to be a vital component of a medical school. In terms of origins and growth, the College of Medicine Library can be divided into three stages: the embroynic stage from 1991 to 2003, the youthful stage from 2003 to 2013, and finally the mature and ambitious stage from 2013 to the present. The founder of the College Library was the industrious Raphael Masanjika, the first COM libarian, from 1991 to 2003. He was later followed by Mrs. Gift Kadzamira, who served as college librarian from 2003 to 2006. From 2006 to the present, Diston Chiweza has been the college librarian.

The years 1991 to 2003 were the formative years years of the COM Library. The foundations were being laid and standards defined. There was a need to find answers to the key question: What kind of medical library do we want?' When the COM opened it doors in 1991 there was one professional librarian, four library assistants, four library security guards, one medical photographer, and one audiovisual technician. This was to remain the number of Library staff throughout the period of 1991 to 2003. This initial period saw the COM Library grow in terms of collection. By the end of this time it had developed clear sections, such as the Periodical section (which included bound periodicals that were bought as such through benchmarking with other medical schools elsewhere), the Open Books section (which could be borrowed out), and the Audio-Visual Collection. By the end of 2003, the COM Library had grown to 18,000 titles and volumes. This kind of stock growth needed a strategy, given that the COM opened its doors without a library building. From 1991 to 2003, the COM used borrowed space at The Polytechnic, another college of the University of Malawi, located about one kilometre away. The migration from The Polytechnic Library in 2003 to the old anatomy laboratory at the Mahatma Gandhi Campus meant that the COM Library now had more space to grow its collection than before. The limited space had constrained the amount of collections to just under 18,000.

The years 2003 to 2013 were the transformational years in which the library diversified its predominantly medical collection to include other subjects, such as pharmacy, laboatory sciences, and health services management. The collection grew to 20,000 within this period. This rapid growth was in response to the new programmes that were being introduced at the College. For instance, by the end of 2003, the MPH programme had been introduced under the leadership of Cam Bowie. Later came the Master of Medicine (MMED) programme in Internal Medicine, and by the 2006-07 academic year, an undergraduate pharmacy programme was established.

By 2013, the COM had grown from single founding faculty to the three that currently make up the institution. From 2013 to the present day, we have seen the COM Library continue to grow in both size and prominence. The Library is now located at the large and spacious John Chiphangwi Learning and Resource Center (JCLRC). With the new space at the JCLRC and the increasing student number from a dozen in 1991 to at least 1,500 students, the number of staff has increased to accommodate all of these developments.

\section{Looking into the future}

Although Malawi continues to lack the required number of medical doctors in both the private and public health sectors, the acute shortage has eased signficantly. Each year we are able to produce about 60 medical doctors into the market, as well as between 20 and 30 medical laboratory scientists, health services managers, public health specialists, pharmacists, and physiotherapists. The increase in the number of specialists trained, and the new programmes and infrastructure developed to train them, were largely organised through joint funding from the Global Fund, the government of the Kingdom of Norway, and the Malawi government.

The popularity of public health specialities has been observed from the early times of the College. ${ }^{9}$ While our output in the 
clinical specialties continues to grow, the numbers are small. We graduate between three and five clinical specialties each year, a number that is rather too low to meet the growing needs in clinical service, teaching and research, and leadership and management. This is an area that we have to invest in even more, but the limited equipment and diagnostic and treatment consummables are formidable constraints.

The foundations of the COM have been set. The research foundations laid by Robin Broadhead, Malcolm Molyneux, ${ }^{12,13}$ Ken Maleta and others are solid. Although the public health services of the country continue to experience shortages of highly skilled health professionals, the bottleneck is not just the absence of well-trained health professionals. Rather, the public health system is experiencing challenges in terms of availability of resources to hire new doctors and other health professionals. As a country, we will contribute to finding long-term solutions to this new problem. Preparing our graduates for the private sector and research environment will need to take centre stage.

\section{Acknowledgements}

The Malawi College of Medicine was initially funded by the governments of Malawi, Britain (through its Overseas Development Agency, ODA), and West Germany, with technical support from the World Health Organization (WHO). The Australian International Developnment Bureau (AIDAB), now AUSAID (Australian Aid for International Development), part-funded the students who went to Flinders Medical School. Further, much of the infrastructure was funded by the Global Fund, through the National AIDS Commisison of Malawi, and the Kingdom of Norway, through the Royal Norwegian Embassy in Lilongwe (Funding support Phase I to Phase IV). The Fogarty Programme of the National Institutes of Health (United States) has trained most of the leaders in public health and epidemiology within the College.

\section{References}

1. Anonymous. Malawi to have school of Medicine. Daily Times, 11th August 1982,quoted in the Daily Times of 11th August 2016, p8

2. Dahlenburg GW. Letter from ... Malawi: the first year of the College of Medicine of the University of Malawi. Trop Doct. 1993;23(1):4-6.

3. Muula AS, Broadhead RL. South Africa's role in medical training in Malawi. S Afr Med J. 2003 Feb;93(2):119-20.

4. Broadhead RL, Muula AS. Creating a medical school for Malawi: problems and achievements. BMJ. 2002;325(7360):384-7.

5. Muula AS, Broadhead RL. The Australian contribution towards medical training in Malawi. Med J Aust. 2001;175(1):42-7.

6. Al-Gahtany M, Binitie O. Adeloye-odeku disease in aseer region of saudiarabia. J West AfrColl Surg. 2011;1(1):113-20.

7. Adeloye A. Congenital dermoid cyst of anterior fontanelle (AdeloyeOdeku disease). Natl Med J India. 1994;7(3):123-5.

8. Yilmaz B, Urgun K, Eksi MS, Tanrikulu B, Bayri Y. Bubble over the head: Adeloye-Odeku disease in a Turkish child-case report. Turk Neurosurg. 2014;24(4):579-82. doi: 10.5137/1019-5149.JTN.905013.0.

9. Muula AS, Broadhead RL. The first decade of the Malawi College of Medicine: a critical appraisal. Trop Med Int Health. 2001;6(2):155-9

10. Adeloye A. The Malawi "hybrid" medical graduates (1992-1998). East and Central African Journal of Surgery, 2000; 5(2): 63-9

11. Muula AS. Every Country or State Needs Two Medical Schools. Croat Med J. 2006; 47(4): 669-672.

12. Broadhead RL. Malcolm Molyneux: beyond the scientist. Trans R Soc Trop Med Hyg. 2009;103Suppl 1:S23-5. doi: 10.1016/j. trstmh.2009.02.001..

13. Mwandumba HC. Research capacity development in Malawi: Malcolm Molyneux's role. Trans R Soc Trop Med Hyg. 2009 Apr;103Suppl 1:S19-22. doi: 10.1016/j.trstmh.2009.01.017. 